\title{
ЦИФРОВАЯ ЭКОНОМИКА В РОССИИ: ПРОБЛЕМЫ И ПЕРСПЕКТИВЫ РАЗВИТИЯ
}

\author{
Дзюба С.А., профессор ИНИТУ, г. Иркутск, Россия \\ Трофимович А.А., магистрант ИРНИТУ, г. Иркутск, Россия
}

Аннотащия: В статье рассмотрены сущность и значение цифровой экономики как качественно нового уровня в развитии социально-экономических процессов; рассмотрены риски и проблемы, а также перспективы развития цифровой экономики в России.

Ключевые слова: цифровая экономика, информационные технологии, цифровая платформа.

Человечество шагнуло в эпоху больших перемен. В ближайшем будущем основные сферы его жизни-экономика и менеджмент, наука и безопасность-будут испытывать новую форму и новое содержание. Человек будет другим, что предполагает трансформацию социальных отношений. Одним из ключевых особенностей будущего мира служит проникновение цифровых технологий в нашу жизнь. Это связано с успехами в области микроэлектроники, информационных технологий и телекоммуникаций. Таким образом, цифровизация это процесс, который нельзя прекратить, и он становится объективным и неизбежным. [1]

Системой экономических, социальных и культурных отношений, которые реализуются с помощью цифровых ИКТ, является цифровая экономика.[2,3] Она фокусируется не только на создании условий, необходимых для появления революционных и перспективных новых цифровых технологий, но и на применении инновационных бизнесмоделей, торговли, логистики и производства. Цифровые технологии изменяют модель деятельности компании, иными словами методы и процедуры реализации корпоративной стратегии в повседневной жизни, особенно в банковском и телекоммуникационном секторах, увеличивают эффективность инвестиций и предлагают новые возможности на рынке. [4]

В дальнейшем "цифровая" (электронная) экономика может стать тем инструментом, осуществляющим масштабную мечту о свободе людей, которые обречены на тяжелый физический труд.[5,6] Будут предоставляться огромные возможности для творчества, науки (фундаментальной и прикладной) и искусства. Внезапно для многих "советская" модель интеллектуального общества будет востребована.

На сегодняшний день необходимо осознать, описать, утвердить и реализовать новый проект "цифровой" (электронной) экономики для того, чтобы стало возможным такое оптимистичное будущее. Целенаправленное и продуманное движение в этом направлении позволит не допустить зависимости технологической и оперативной деятельности отечественной экономики от иностранных цифровых платформ, стандартов и технологий, а также от активного и неконтролируемого обращения виртуальных валют (криптовалют). Следует четко видеть проблемы, а также необходима последовательная политика действий, чтобы вовремя воспользоваться открывающимися возможностями и сохранить свой цифровой и, следовательно, реальный суверенитет.[7]

Новые риски и проблемы связаны с развитием и широким внедрением "цифровых" технологий:

- Угроза "цифровому суверенитету" страны и переоценка роли государства в трансграничном мире " цифровой экономики";

- Нарушение конфиденциальности / потенциальный мониторинг граждан;

- Снижение уровня безопасности данных; 
рабочих мест;

- Сокращение числа низкоквалифицированных и среднеквалифицированных

- Повышение уровня сложности бизнес-моделей и схем взаимодействия;

- Резкое увеличение конкуренции во всех секторах экономики;

- Изменение в моделях поведения производителей и потребителей;

- Необходимость пересмотра административного и налогового кодексов.

Сейчас в России быстро развивается цифровая экономика. С 2011 по 2018 год общий объем российской цифровой экономики возрос на 59\%, увеличившись в девять раз быстрее, чем ВВП страны. В итоге доля цифровой экономики достигла 3,9\% ВВП в 2015 году, что является значительно потенциальным ростом.[8] Это особенно видно за пределами показателей других стран (рис. 1). Поэтому для России необходимо ускорить темпы цифровизации и достичь намеченной цели к 2025 году - увеличить объём цифровой экономики.

Трлн руб.

Проценты от уровня 2011 г.

\section{Экономика в целом}

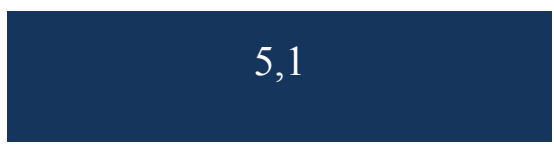

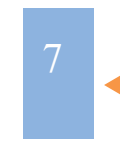
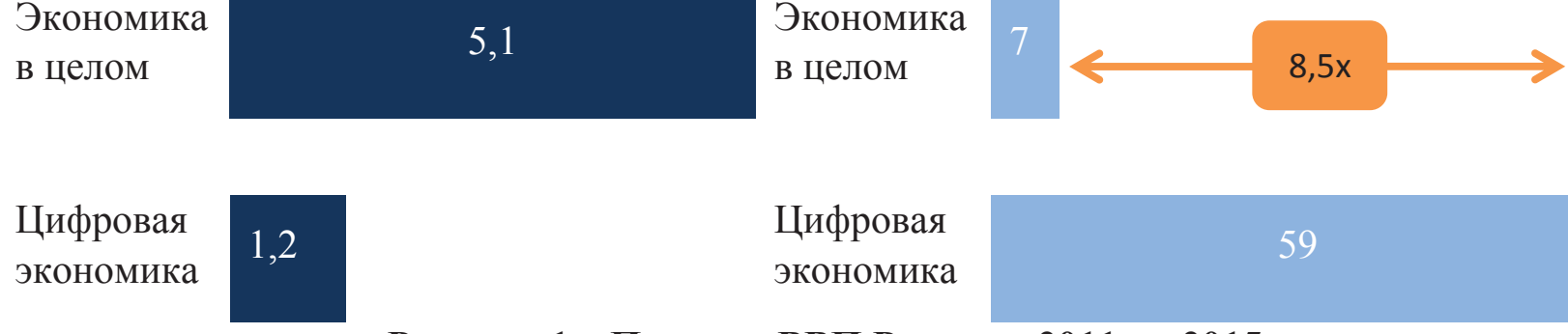

Цифровая

экономика

\section{9}

Рисунок 1 - Прирост ВВП России с 2011 по 2015

В России цифровая экономика получила сильный толчок за последние годы. Некоторые достижения частных компаний, преобразовавшие рынок труда, при помощи государств создали беспрецедентные инфраструктурные проекты, увеличивающие уровень досягаемости цифровых услуг для граждан и бизнеса, распространенным является интернет, широкополосная и мобильная связь.[9] Тем не менее, она всё также уступает другим странам, которые занимают лидирующие позиции по численным показателям цифровой экономики, особенно Европейского Союза (рис. 2).

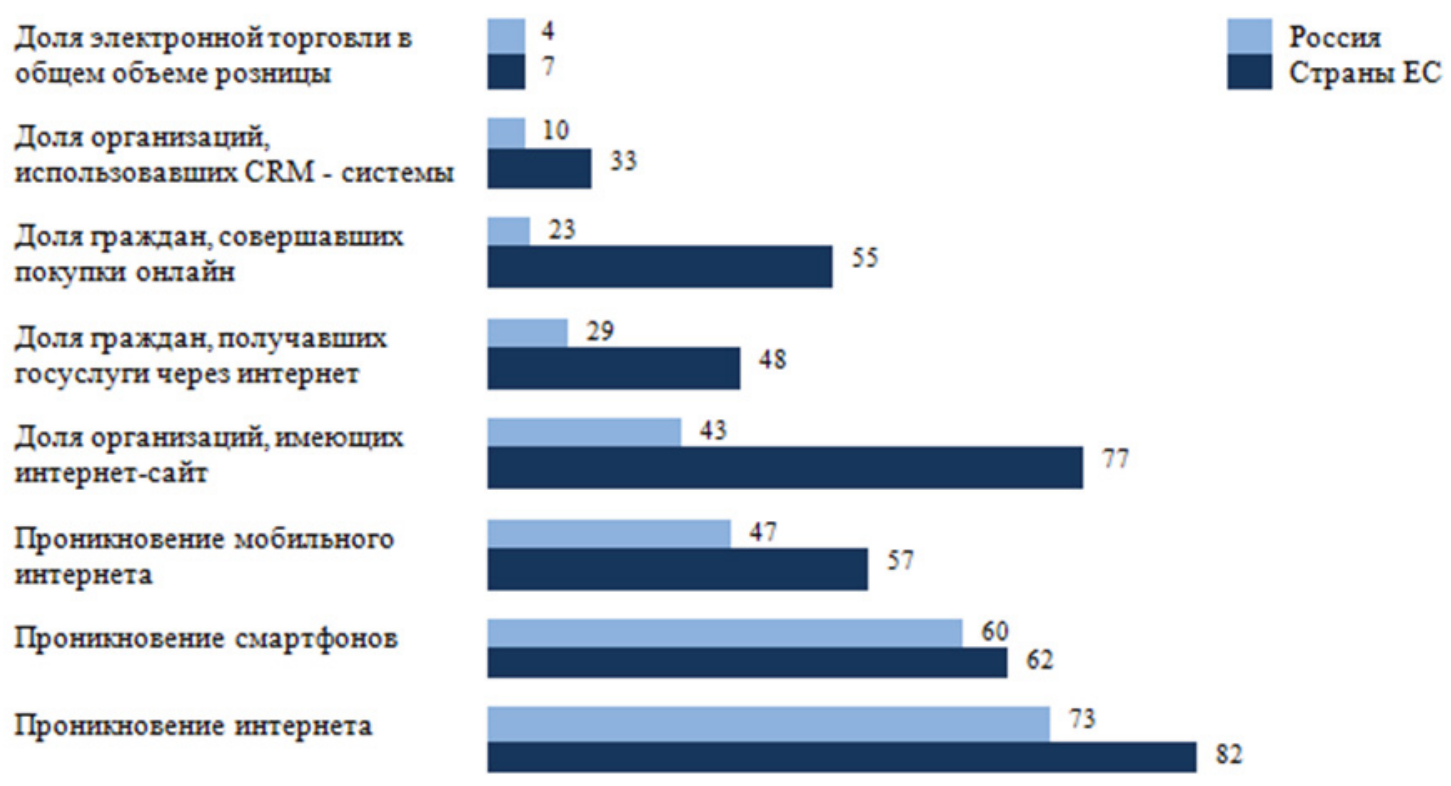

Рисунок 2 - Показатели развития цифровой экономики 
Сегодня значение такого лидирующего показателя для развития цифровой экономики как отношение объема цифровой экономики к ВВП страны набирает 3,9\%, что почти в 2-3 раза ниже, чем в странах, выбранных для сравнения.[10] Затраты цифровых домохозяйств составляют 2,6\% ВВП России - это важное вложение в развитие новых технологий, но остаётся меньше среднего показателя преимущественно развитых стран $(3,6 \%)$. Часть государственных расходов и частных инвестиций в ВВП меньше, чем в соответствующих странах, а цифровой экспорт в четыре раза ниже импорта. Если российские вложения в ИКТ, вместе с цифровыми расходами домашних хозяйств и инвестиции предприятий и органов государственного управления, сравнивать со средним уровнем стран, то часть цифровой экономики в России наберёт 5,9\% ВВП, что позволяет занять место России между Индией и Китаем (рис. 3).

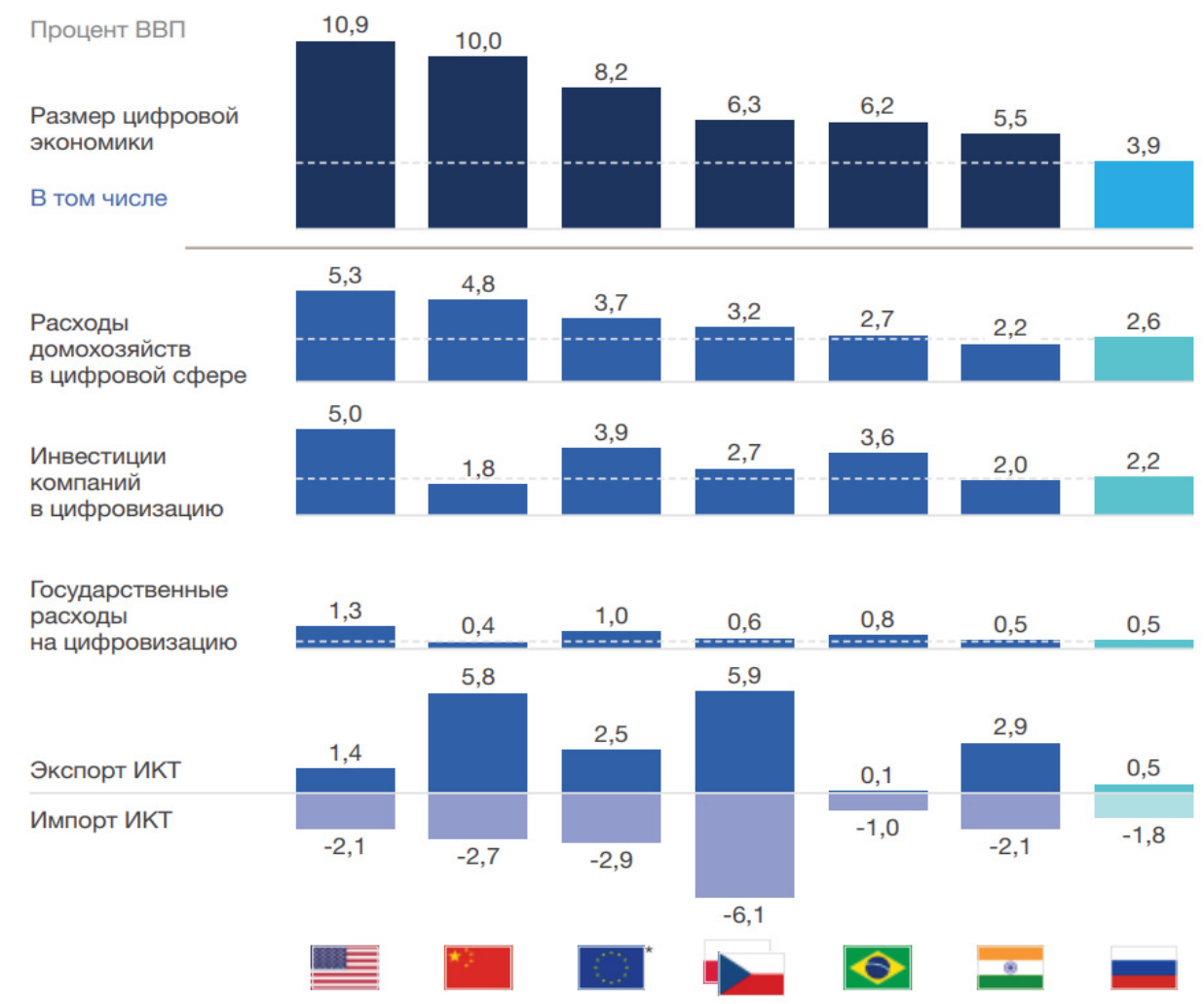

Рисунок 3 - ВВП России и его составляющие в сравнении с другими странами

Итак, современная экономика формируется под мощным воздействием процессов информатизации, что повлекло создание концепции цифровой экономики. Цифровая экономика может предоставить постоянное развитие и отчётливость руководства бизнесом и государством на всех уровнях.

\section{Список используемой литературы}

1. Коновалова М.Е., Кузьмина О.Ю., Суриков К.Ю. Цифровизация экономики России как условие повышения её конкурентоспособности // Экономика и управление собственностью. 2017. №4. С. 5-9.

2. Ефимушкин В.А., Ледовских Т.В., Щербакова Е.Н. Инфокоммуникационное технологическое пространство цифровой экономики // Т-Comm: Телекоммуникации и транспорт. 2017. №5. C. 15-20. URL Научная библиотека КиберЛенинка. 
3. Тимофеев Р.А., Минибаева Д.Р., Ехлакова Е.А. Цифровая экономика как драйвер устойчивого роста отечественной экономики // Вестник экономики, права и социологии. 2018. №1. C. 42-45.

4. Капранова Л.Д. Цифровая экономика в России: состояние и перспективы развития // Экономика. Налоги. Право. 2018. №2. Том 11. С. 58-69.

5. Бианкина А.О. Цифровые технологии и их роль в современной экономике // Экономика и социум: современные модели развития. 2017. №16. С. 15-25.

6. Борщ Л.М. Модернизация экономики: технологии vs человек // Известия Уральского государственного экономического университета. 2018. №3. Том 19. С. 42-54.

7. Носова С.С., Рябцун В.В., Норкина А.Н. Цифровая экономика как модель современного социально-экономического развития России // Экономика и предпринимательство. 2018. №3(92). С. 26-32.

8. Быков А.А. О рисках цифровой экономики // Проблемы анализа риска. 2017. №6. Том 14. C. 4-5.

9. Сагынбекова А.С. Цифровая экономика: понятие, перспективы, тенденции развития в России // Теория. Практика. Инновации. 2018. №4(28). С. 255-267.

10. Асадуллина А.В. Цифровая экономика в России: Текущий статус и проблемы развития // Российский внешнеэкономический вестник. 2018. №6. С. 98-112.

(C) Дзюба С.А., Трофимович А.А., 2019 г. 